\title{
Autosomal recessive spastic paraplegia type 35
}

INSERM

\section{Source}

INSERM. (1999). Orphanet: an online rare disease and orphan drug data base. Autosomal recessive spastic paraplegia type 35. ORPHA:171629

Autosomal recessive spastic paraplegia type 35 is a rare form of hereditary spastic paraplegia characterized by childhood (exceptionally adolescent) onset of a complex phenotype presenting with lower limb (followed by upper limb) spasticity with hyperreflexia and extensor plantar responses, with additional manifestations including progressive dysarthria, dystonia, mild cog nitive decline, extrapyramidal features, optic atrophy and seizures. White matter abnormalities and brain iron accumulation have also been observed on brain magnetic resonance imaging. 